\title{
Surgical treatment of Type II odontoid fractures: anterior odontoid screw fixation or posterior cervical instrumented fusion?
}

\author{
Andrei F. Joaquim, MD, PhD, ${ }^{1}$ and Alpesh A. Patel, MD² \\ 1Department of Neurology, State University of Campinas (UNICAMP), São Paulo, Brazil; and 2Department of Orthopaedic \\ Surgery, Northwestern University, Chicago, Illinois
}

\begin{abstract}
Odontoid fractures comprise as many as $20 \%$ of all cervical spine fractures. Fractures at the dens base, classified by the Anderson and D'Alonzo system as Type II injuries, are the most common pattern of all odontoid fractures and are also the most common cervical injuries in patients older than 70 years of age. Surgical treatment is recommended for patients older than 50 years with Type II odontoid fractures, as well as in patients at a high risk for nonunion. Anterior odontoid screw fixation (AOSF) and posterior cervical instrumented fusion (PCIF) are both well-accepted techniques for surgical treatment but with unique indications and contraindications as well as varied reported outcomes. In this paper, the authors review the literature about specific patients and fracture characteristics that may guide treatment toward one technique over the other.
\end{abstract}

AOSF can preserve atlantoaxial motion, but requires a reduced odontoid, an intact transverse ligament, and a favorable fracture line to achieve adequate fracture compression. Additionally, older patients may have a higher rate of pseudarthrosis using this technique, as well as postoperative dysphagia. PCIF has a higher rate of fusion and is indicated in patients with severe atlantoaxial misalignment and with poor bone quality. PCIF allows direct open reduction of displaced fragments and can reduce any atlantoaxial subluxation. It is also used as a salvage procedure after failed AOSF. However, this technique results in loss of atlantoaxial motion, requires prone positioning, and demands a longer operative duration than AOSF, factors that can be a challenge in patients with severe medical conditions. Although both anterior and posterior approaches are acceptable, many clinical and radiological factors should be taken into account when choosing the best surgical approach. Surgeons must be prepared to perform both procedures to adequately treat these injuries. http://thejns.org/doi/abs/10.3171/2015.1.FOCUS14781

KEY WORDS odontoid fractures; approach; treatment; anterior odontoid screw fixation; posterior cervical instrumented fusion

$\mathrm{O}$ DONTOID fractures comprise as many as $20 \%$ of all cervical fractures..$^{9,33,38}$ The incidence of odontoid fractures increases substantially in older patients and represents the most common cervical fractures in patients older than 70 years. ${ }^{10,37}$ In 1974, Anderson and D'Alonzo published the most commonly used classification for odontoid fractures. ${ }^{3}$ They divided the fractures into 3 categories: 1) Type I, fracture through the upper portion of the dens (tip); 2) Type II, fracture at the base of the dens, in the junction with the axis body; and 3) Type III, fracture extending into the body of the axis, possibly also involving the atlantoaxial joint.
Type II fractures are the most common odontoid fracture, occurring in $65 \%-74 \%$ of the cases., ${ }^{3,6,28}$ These fractures have similar biomechanical properties as transverse ligament injuries, i.e., a loss of the translational restriction of $\mathrm{C}-1$ on $\mathrm{C}-2$, creating the potential for spinal cord injury and severe late craniocervical deformities when healing is not obtained. $3,21,22,27$

Treatment strategies for odontoid fractures can vary from nonoperative management with an external immobilization (such as a cervical collar, Minerva, and other cervicothoracic orthoses, and halo orthosis), to operative management with anterior odontoid screw fixation (AOSF)

ABBREVIATIONS AOSF = anterior odontoid screw fixation; PCIF = posterior cervical instrumented fusion.

SUBMITTED November 19, 2014. ACCEPTED January 21, 2015.

INCLUDE WHEN CITING DOI: 10.3171/2015.1.FOCUS14781.

DISCLOSURE Dr. Patel has direct stock ownership in Amedica, Vital5, and Cytonics, and has served as a consultant to DePuy, Amedica, Biomet, Stryker Spine, Zimmer, and Ulrich. 
or posterior cervical fusion with or without supplemental screw fixation. ${ }^{6-8,21,22}$

In this paper, we review the potential surgical indications for Type II odontoid fractures with an emphasis on choosing the best surgical approach for treatment (anterior vs posterior approach). Advantages and disadvantages of each approach are discussed in detail.

\section{Surgical Indications for Type II Odontoid Fractures}

The union rate of Type II odontoid fractures is directly related to the treatment performed. Nonsurgical treatment with a cervical collar or halo vest has a nonunion rate of as high as $40 \% .{ }^{31}$ For this reason, surgical treatment is especially indicated in patients who have a higher risk for nonunion. In this context, surgical treatment with AOSF or posterior cervical instrumented fusion (PCIF) increases the fusion rate to more than $80 \%$ in many patient series. ${ }^{1,31}$ Some authors have reported up to $100 \%$ healing with posterior $\mathrm{C} 1-2$ arthrodesis with PCIF. ${ }^{5}$ Identifying patients at high risk for nonunion is critical to avoiding the late complications of nonunion while balancing the risk of surgical management.

Some risk factors for nonunion are well established. Lennarson et al. performed a case-control study (Level II evidence) of 33 patients with Type II odontoid fractures. ${ }^{24}$ They reported that in patients older than 50 years, the risk of nonunion was 21 times greater than in younger patients $\left(\mathrm{p}=0.002,2\right.$-tailed Fisher's exact test). ${ }^{24}$ The authors concluded that older patients may benefit from surgical treatment to improve fusion rates if the procedure is not contraindicated by other clinical reasons. Other factors have also been reported to be associated with nonunion and failure of conservative treatment, such as degree of comminution in the base of the dens, fracture displacement, fracture alignment, and rupture of the transverse ligament. ${ }^{16,21,22}$

Hadley et al. described an additional fracture pattern (Type IIA), reported to be present in 3 of 62 Type II fractures. This Type IIA fracture was highly unstable and was characterized by a comminuted fracture of the base of the odontoid with associated free fracture fragments. ${ }^{15}$ These authors recommended surgical treatment of this fracture pattern. Greene et al. reported in a retrospective review that Type II odontoid fractures with odontoid displacement of $6 \mathrm{~mm}$ or more were associated with nonunion (chi-square $=33.74, \mathrm{p}<0.0001$ ), and early surgical treatment was recommended. ${ }^{14}$ Platzer et al. reported the results of 90 patients with Type II fractures. These authors identified risk factors (all $\mathrm{p}<0.05$ ) for failure of halo immobilization: older patients, displaced fractures $(>2 \mathrm{~mm})$, secondary loss of reduction, and delayed treatment. ${ }^{30}$ Potential surgical indications for Type II odontoid fractures, which are primarily based on the risk of nonunion with conservative treatment, are summarized in Tables 1 and 2.

\section{Specific Considerations in Older Patients}

Because odontoid fractures are common in older patients, many authors have reported on their experience
TABLE 1. Potential surgical indications for Type II odontoid fractures

Patients $>50$ years, while considering the risk of severe surgical
complications in patients $>80$ years old
$\begin{aligned} & \text { Patients with Type IIA fractures (comminuted fracture on the dens } \\ & \text { base) }\end{aligned}$
Fracture gap $>2 \mathrm{~mm}$
Odontoid displacement $>5 \mathrm{~mm}$
Lack of maintaining an acceptable reduction and fracture alignment
with an external immobilization device

in this population. Smith et al. reported the results of a retrospective cohort analysis of octogenarians (patients $>$ 80 years old). ${ }^{34} \mathrm{~A}$ total of 32 patients underwent operative treatment (10 anterior and 22 posterior approaches) and 20 were treated conservatively. Patients who underwent operative treatment had longer hospital stays (mean 22.8 vs 11.2 days, respectively; $\mathrm{p}<0.05$ ) and higher complication rates ( $62 \%$ vs $35 \%$, respectively; $p<0.05$ ), but in both groups the acute in-hospital mortality rate was simi$\operatorname{lar}(15 \%$ in the nonsurgical group and $12.5 \%$ in the surgical group; $\mathrm{p}>0.05)$. Comorbidities were similar in both groups, as was fracture displacement $(\mathrm{p}>0.05)$. These investigators concluded that in these patients, both operative and nonoperative treatments are associated with high morbidity and mortality, but conservative treatment may be considered due to fewer complications and similar outcomes.

With regard to radiological outcomes in older patients, some authors have reported that a fibrous union with radiological stability may be considered acceptable as a good outcome. ${ }^{23}$ Lastly, there are studies suggesting that halo vests result in worse outcomes when compared with cervical collars in older patients, including a significant mortality rate during hospitalization (up to $28.6 \%$ )..$^{8,10,16,26}$ Halo vest immobilization in older patients is associated with pneumonia and cardiac arrest; 26,36 for this reason, it may be prescribed only as a last resource in this fragile population. Instead, conservative treatment may be best addressed through a rigid cervical collar.

\section{Choosing the Surgical Approach: AOSF Versus PCIF}

Once surgical treatment is recommended, surgeons should choose the best surgical approach. According to the recent Guidelines of the American Association of

TABLE 2. Specific considerations for treatment of odontoid Type II fractures in patients older than 80 years

Extremely older patients ( $>80$ years) have higher morbidity and mortality rates regardless of the treatment performed

Halo vest is associated with higher rates of complications in older patients

Conservative treatment with a rigid cervical collar may be an acceptable treatment for this age group 
Neurological Surgeons and the Congress of Neurological Surgeons, when surgery is indicated, both anterior and posterior atlantoaxial instrumented fusion are acceptable methods for treating Type II odontoid fractures..$^{32}$ However, the decision of which approach to use is influenced by individual clinical and radiological factors. For this reason, we present the primary advantages and limitations of each approach in the next section, as well as the best indications for each.

\section{Anterior Odontoid Screw Fixation}

Anterior odontoid screw fixation is an osteosynthetic technique that provides immediate stability, preserving the majority of the remaining $\mathrm{Cl}-2$ motion. ${ }^{7}$ Most of the available evidence is based on case series. While not all patients with Type II odontoid fractures are candidates for AOSF, the reported union rates are high, varying from $80 \%$ to as high as $100 \%$ ? Indications for AOSF include a favorable fracture line (a fracture line from anterosuperior to posterosuperior), as well as good fracture reduction and alignment. Contraindications include fracture comminution, severe cervicothoracic kyphosis, severe osteoporosis, late fractures, and ligament transverse rupture..$^{1,2,17}$

Apfelbaum et al. reported the results of 147 patients who underwent AOSF for recent ( $\leq 6$ months postinjury, $\mathrm{n}$ $=129$ ) or late odontoid fractures ( $\geq 18$ months postinjury, $\mathrm{n}=18) .{ }^{4}$ The mean follow-up duration was 18.2 months. In recent fractures, the overall union rate was $88 \%$, compared with $25 \%$ in late injuries $(\mathrm{p} \leq 0.05)$. Bone union was independent $(\mathrm{p} \geq 0.05)$ of other factors, such as age, sex, number of screws placed (1 or 2), and the degree or the direction of odontoid displacement. The authors concluded that, although AOSF was effective and safe for early odontoid fractures, this technique should be reserved for early fractures. In patients who had remote injuries $(\geq 18$ months postinjury), AOSF may not be the preferred procedure.

Platzer et al. performed a retrospective comparative study of 110 patients who underwent anterior doublescrew fixation of their odontoid fractures. ${ }^{29}$ They compared the functional and radiological outcomes between patients younger than 65 years (Group A) and older than 65 years (Group B). A total of 95 patients had returned to their preinjury activity level. The outcome, assessed using the Smiley-Webster scale, was similar in both groups, but the nonunion rate was higher in the geriatric patients $(12 \%)$ compared with the younger patients $(8 \%)$.

\section{Use of 1 or 2 Screws}

Jenkins et al. compared the safety and efficacy of using 1 versus 2 screws for anterior odontoid fixation..$^{18}$ They retrospectively reviewed 42 patients from a single institution: 20 patients treated with a single screw, with an average age of 54 years, compared with 22 patients treated using 2 screws, with an average age of 64 years. There was no significant difference in the union rate (assessed using dynamic radiographs) between the 1- or 2-screw groups, which were $81 \%$ and $85 \%$, respectively $(\mathrm{p}>0.05)$. Another study that compared the efficacy of the 1- versus 2 -screw technique was performed by Dailey et al., which reported different results. These authors retrospectively reviewed 57 patients over the age of 70 that underwent AOSF. Union was evaluated utilizing flexion-extension radiographs to assess stability and was defined as bone union, fibrous union, and nonunion. Complications were also documented. A total of $81 \%$ of the patients had stability based on the author's criteria. Two-screw fixation was associated with stability in $96 \%$ of patients at the final follow-up evaluation compared with $56 \%$ of the patients using 1 screw. The authors, however, reported a high rate of patients $(25 \%)$ requiring a feeding tube in the immediate postoperative period, and 19\% having aspiration pneumonia that required antibiotics. This study demonstrates a higher rate of radiographic stability with AOSF utilizing 2 screws, and it also reveals a high rate of dysphagia and eating difficulties postoperatively.

Similar complications after AOSF in older patients regarding dysphagia problems were reported by Vasudevan et al. ${ }^{38}$ These authors evaluated immediate complications after AOSF, such as postoperative dysphagia and pneumonia, in 30 patients with Type II odontoid fractures. Complications included pneumonia in 9 patients (30\%), gastrostomy tube placement due to swallowing problems in 13 patients (43\%), and vocal cord paralysis in 1 patient (3.3\%). Patients over the age of 75 accounted for 12 (92\%) of 13 gastrostomy tube placements and $8(88.9 \%)$ of the 9 pneumonias. There were statistically significant differences between rates of gastrostomy tube placement $(\mathrm{p}<$ $0.02)$ and pneumonias $(\mathrm{p}<0.001)$ for the older patients compared with younger patients. The authors concluded that although AOSF was effective, there was a high risk of postoperative dysphagia in older patients. An illustrative case of AOSF is presented in Fig. 1.

\section{Characteristics of AOSF}

Based on these data, AOSF is highly effective for treating odontoid fractures, with union rates of $80 \%-100 \%$. AOSF should be reserved for early odontoid fractures $(<6$ months after injury), as remote injuries have a low union rate $(25 \%)$. There is a greater chance of nonunion in older compared with younger patients after AOSF. In the general population, AOSF may have the same efficacy using 1 or 2 screws, but in patients over 70 years old, 2 screws may have a greater rate of union. Finally, AOSF in older patients yields a high incidence of severe dysphagia and early pneumonia after surgery.

\section{Posterior Cervical Atlantoaxial Instrumented Fusion}

Posterior stabilization of the atlantoaxial joint can be performed with many different techniques, using wiring or screws. ${ }^{10-12}$ Compared with wiring techniques, screw fixation for atlantoaxial stabilization improved fusion rates and did not require a postoperative orthosis. ${ }^{10-12}$ The most common screw fixation techniques are the $\mathrm{Cl}-2$ transarticular screw, described by Magerl and Seeman in 1987, as well as C-1 lateral mass screw fixation described by Goel and Laheri, associated with a C-2 screw (lamina, pars, or pedicle). ${ }^{13,19,20,25}$

Posterior techniques are indicated when there is a con- 


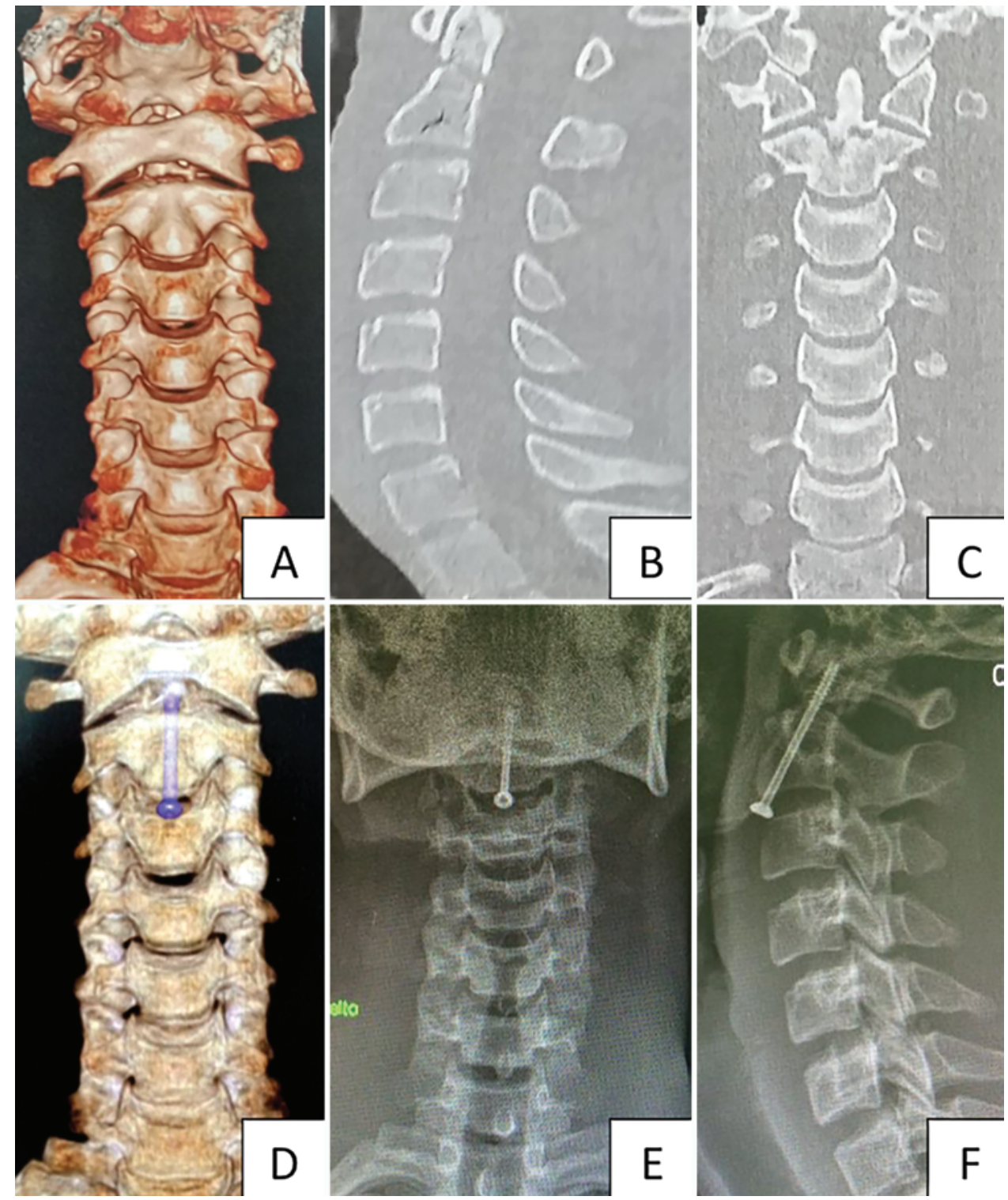

FIG. 1. Images from a 52-year-old man involved in a car accident. This patient had severe neck pain without neurological deficits. A: Three-dimensional CT scan reconstruction with a fracture line on the dens base. B and C: Sagittal (B) and coronal (C) CT reconstructions showing a Type II odontoid injury with a horizontal line fracture. The patient underwent AOSF. D-F: Postoperative 3D CT scan reconstruction (D), as well as postoperative anteroposterior (E) and lateral (F) cervical radiographs showing odontoid screw fixation.

traindication for AOSF, such as a reverse fracture line (anteroinferior to posterosuperior of dens base), transverse ligament rupture, nonreducible fractures, nonunions (remote injuries), inappropriate body habitus, severe cervicothoracic kyphosis, and osteoporosis. ${ }^{1,2,17}$ Patients in whom postoperative complications such as dysphagia and pneumonia are a concern may instead be indicated for a posterior technique. Lastly, when AOSF fails, with screw pullout or loss of fracture alignment, posterior screw fixation is a salvage procedure. ${ }^{3}$

In a retrospective series of 29 consecutive patients over 65 years, Anderson and D'Alonzo compared 11 patients who underwent AOSF and 7 who underwent posterior C1-2 fusion. ${ }^{3}$ Ten patients were treated conservatively due to minimally displaced fractures or complicating medical conditions. At the final follow-up evaluation (average 51 months, range $24-89$ months) the authors reported that all 7 patients with posterior fusion healed, whereas just 8 (73\%) of the 11 treated with AOSF healed, and only after a complicated course of events. In 2 patients, irreducible fracture and limited access led to conversion from AOSF to PCIF. Another 2 patients suffered screw loosening and back out. Two patients had nonunions and 1 patient had severe motion-related pain from the $\mathrm{C} 1-2$ articulation. Six of the 10 patients treated nonsurgically had nonunions and 2 underwent late surgery. Based on this experience, the authors proposed that posterior fusion had fewer complications and a high healing rate. 


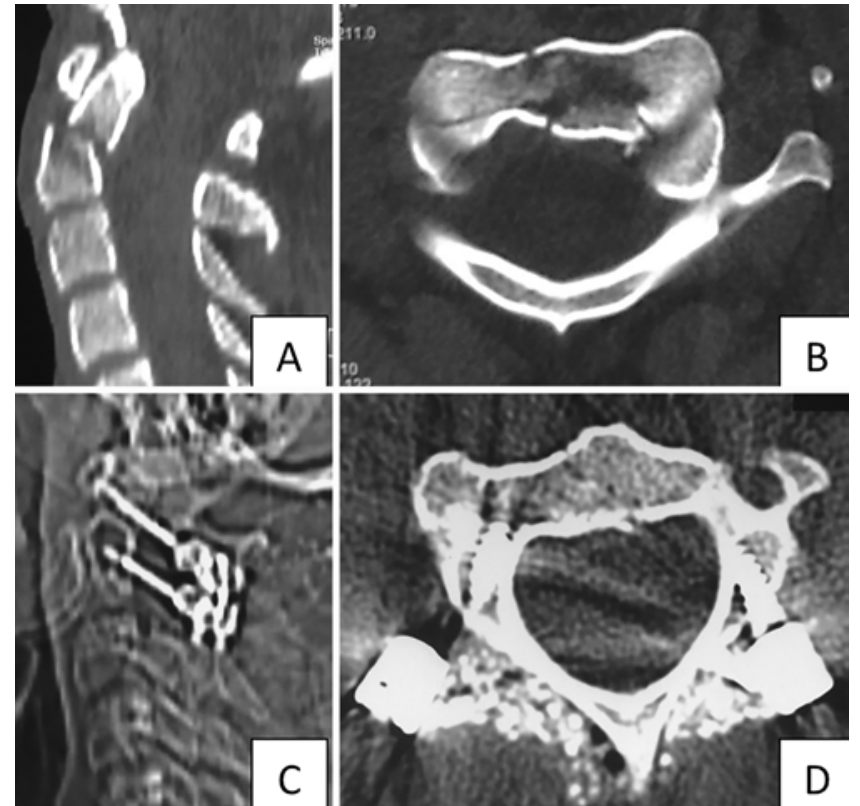

FIG. 2. Images in an 18-year-old man involved in a motorcycle accident with a Type II odontoid fracture and posterior dens displacement. This patient underwent an operation 1 month after injury due to other traumatic brain injury and the fracture did not maintain its alignment. For this reason, he underwent a posterior C-1 lateral mass to C-2 pedicle screw fixation with posterior arthrodesis and bone graft harvest from the iliac crest. A: Sagittal CT scan reconstruction with posterior dens displacement. B: Axial CT scan showing C-2 comminution on the dens base. C: Postoperative sagittal CT scan with proper dens alignment and $\mathrm{C} 1-2$ screw fixation. $\mathrm{D}$ : Axial CT scan showing $\mathrm{C}-2$ pedicle screws placed properly.

Posterior atlantoaxial screw fixation has higher fusion rates but eliminates the normal $\mathrm{C} 1-2$ rotatory motion, which is responsible for approximately $50 \%$ of cervical rotary motion and $10 \%$ of cervical flexion-extension motion. ${ }^{35}$ Complications of PCIF may include blood loss, vertebral artery injury, infection, dural tears, and others. An illustrative case of PCIF is presented in Fig. 2.

\section{Characteristics of PCIF}

In summary, PCIF is highly effective for treating odontoid fractures, with fusion rates of up to $100 \%$. Indications for PCIF include an unfavorable fracture line for AOSF, transverse ligament rupture, severe dens displacement, and misalignment and remote fractures. PCIF may also be indicated as a salvage procedure after AOSF failure and in severe osteoporotic patients. In Table 3 we summarized the main indications, risks, and limitations of AOSF and PCIF in a comparative perspective.

\section{Conclusions}

In the surgical treatment of odontoid fractures, both anterior and posterior approaches are available. Each approach has unique indications and contraindications that should be tailored to the individual patient. Both approaches have demonstrated success at achieving fracture stability, but posterior instrumented treatment has the
TABLE 3. Comparison of AOSF versus PCIF

\begin{tabular}{|c|c|c|}
\hline Characteristic & AOSF & PCIF \\
\hline Motion preservation of the atlantoaxial joints & Yes & No \\
\hline Soft-tissue injury & + & $++/+++$ \\
\hline Bone graft requirement & No & Yes \\
\hline Risk of vertebral artery injury & + & ++ \\
\hline Operative time & + & $++/+++$ \\
\hline Blood loss & + & $++/+++$ \\
\hline Limited by fracture morphology & Yes & No \\
\hline Limited by body habitus & Yes & No \\
\hline Limited by the status of the transverse ligament & Yes & No \\
\hline Postop narcotic requirement & + & $++/+++$ \\
\hline Early injuries ( $\leq 6 \mathrm{mos}$ ) & Yes & Yes \\
\hline Remote injuries ( $\geq 18$ mos) & No & Yes \\
\hline $\begin{array}{l}\text { Risk of dysphagia after surgery (especially in older } \\
\text { patients) }\end{array}$ & $++/+++$ & + \\
\hline
\end{tabular}

$+=$ mild $;++=$ moderate $+++=$ strong.

highest reported rate of union while minimizing significant dysphagia associated with anterior approaches.

\section{References}

1. Aebi M, Etter C, Coscia M: Fractures of the odontoid process. Treatment with anterior screw fixation. Spine (Phila Pa 1976) 14:1065-1070, 1989

2. Agrillo A, Russo N, Marotta N, Delfini R: Treatment of remote type II axis fractures in the elderly: feasibility of anterior odontoid screw fixation. Neurosurgery 63:1145-1151, 2008

3. Anderson LD, D'Alonzo RT: Fractures of the odontoid process of the axis. J Bone Joint Surg Am 56:1663-1674, 1974

4. Apfelbaum RI, Lonser RR, Veres R, Casey A: Direct anterior screw fixation for recent and remote odontoid fractures. J Neurosurg 93 (2 Suppl):227-236, 2000

5. Campanelli M, Kattner KA, Stroink A, Gupta K, West S: Posterior C1-C2 transarticular screw fixation in the treatment of displaced type II odontoid fractures in the geriatric population-review of seven cases. Surg Neurol 51:596-601, 1999

6. Clark CR, White AA III: Fractures of the dens. A multicenter study. J Bone Joint Surg Am 67:1340-1348, 1985

7. Dailey AT, Hart D, Finn MA, Schmidt MH, Apfelbaum RI: Anterior fixation of odontoid fractures in an elderly population. J Neurosurg Spine 12:1-8, 2010

8. Denaro V, Papalia R, Di Martino A, Denaro L, Maffulli N: The best surgical treatment for type II fractures of the dens is still controversial. Clin Orthop Relat Res 469:742-750, 2011

9. Dunn ME, Seljeskog EL: Experience in the management of odontoid process injuries: an analysis of 128 cases. Neurosurgery 18:306-310, 1986

10. Elgafy H, Dvorak MF, Vaccaro AR, Ebraheim N: Treatment of displaced type II odontoid fractures in elderly patients. Am J Orthop 38:410-416, 2009

11. Farey ID, Nadkarni S, Smith N: Modified Gallie technique versus transarticular screw fixation in $\mathrm{C} 1-\mathrm{C} 2$ fusion. Clin Orthop Relat Res (359):126-135, 1999

12. Gallie WE: Fractures and dislocations of the cervical spine. Am J Surg 46:495-499, 1939

13. Goel A, Laheri V: Plate and screw fixation for atlanto-axial subluxation. Acta Neurochir (Wien) 129:47-53, 1994 
14. Greene KA, Dickman CA, Marciano FF, Drabier JB, Hadley MN, Sonntag VK: Acute axis fractures. Analysis of management and outcome in 340 consecutive cases. Spine (Phila Pa 1976) 22:1843-1852, 1997

15. Hadley MN, Browner C, Sonntag VK: Axis fractures: a comprehensive review of management and treatment in 107 cases. Neurosurgery 17:281-290, 1985

16. Hanigan WC, Powell FC, Elwood PW, Henderson JP: Odontoid fractures in elderly patients. J Neurosurg 78:32-35, 1993

17. Henry AD, Bohly J, Grosse A: Fixation of odontoid fractures by an anterior screw. J Bone Joint Surg Br 81:472-477, 1999

18. Jenkins JD, Coric D, Branch CL Jr: A clinical comparison of one- and two-screw odontoid fixation. J Neurosurg 89:366370,1998

19. Joaquim AF, Ghizoni E, Anderle DV, de Oliveira E, Tedeschi H: Axis instrumentation: surgical results. Arq Neuropsiquiatr 70:857-863, 2012

20. Joaquim AF, Ghizoni E, Rubino PA, Anderle DV, Tedeschi $\mathrm{H}$, Rhoton AL Jr, et al: Lateral mass screw fixation of the atlas: surgical technique and anatomy. World Neurosurg 74:359-362, 2010

21. Joaquim AF, Patel AP: $\mathrm{C} 1$ and $\mathrm{C} 2$ spine trauma: evaluation, classification and treatment. Contemp Spine Surg 11(3):1-7, 2010

22. Joaquim AF, Patel AP: Occipito cervical trauma: evaluation, classification and treatment. Contemp Spine Surg 11(4):1-5, 2010

23. Koech F, Ackland HM, Varma DK, Williamson OD, Malham GM: Nonoperative management of type II odontoid fractures in the elderly. Spine (Phila Pa 1976) 33:2881-2886, 2008

24. Lennarson PJ, Mostafavi H, Traynelis VC, Walters BC: Management of type II dens fractures: a case-control study. Spine (Phila Pa 1976) 25:1234-1237, 2000

25. Magerl FSCS, Seeman PS: Stable posterior fusion of the atlas and axis by transarticular screw fixation, in Kehr P, Weidner A (eds): Cervical Spine I. New York: Springer-Verlag, 1987,pp 322-327

26. Majercik S, Tashjian RZ, Biffl WL, Harrington DT, Cioffi WG: Halo vest immobilization in the elderly: a death sentence? J Trauma 59:350-358, 2005

27. Mashhadinezhad H, Samini F, Mashhadinezhad A, Birjandinejad A: Clinical results of surgical management in type II odontoid fracture: a preliminary report. Turk Neurosurg 22:583-587, 2012

28. Müller EJ, Schwinnen I, Fischer K, Wick M, Muhr G: Nonrigid immobilisation of odontoid fractures. Eur Spine J 12:522-525, 2003

29. Platzer P, Thalhammer G, Ostermann R, Wieland T, Vécsei V, Gaebler C: Anterior screw fixation of odontoid fractures comparing younger and elderly patients. Spine (Phila Pa 1976) 32:1714-1720, 2007

30. Platzer P, Thalhammer G, Sarahrudi K, Kovar F, Vekszler G, Vécsei $\mathrm{V}$, et al: Nonoperative management of odontoid fractures using a halothoracic vest. Neurosurgery 61:522-530, 2007

31. Robinson Y, Robinson AL, Olerud C: Systematic review on surgical and nonsurgical treatment of type II odontoid fractures in the elderly. Biomed Res Int 2014:231948, 2014

32. Ryken TC, Hadley MN, Aarabi B, Dhall SS, Gelb DE, Hurlbert RJ, et al: Management of isolated fractures of the axis in adults. Neurosurgery 72 (Suppl 2):132-150, 2013

33. Scheyerer MJ, Zimmermann SM, Simmen HP, Wanner GA, Werner CM: Treatment modality in type II odontoid fractures defines the outcome in elderly patients. BMC Surg 13:54, 2013

34. Smith HE, Kerr SM, Maltenfort M, Chaudhry S, Norton R, Albert TJ, et al: Early complications of surgical versus conservative treatment of isolated type II odontoid fractures in octogenarians: a retrospective cohort study. J Spinal Disord Tech 21:535-539, 2008

35. Smith HE, Vaccaro AR, Maltenfort M, Albert TJ, Hilibrand AS, Anderson DG, et al: Trends in surgical management for type II odontoid fracture: 20 years of experience at a regional spinal cord injury center. Orthopedics 31:650-655, 2008

36. Tashjian RZ, Majercik S, Biffl WL, Palumbo MA, Cioffi WG: Halo-vest immobilization increases early morbidity and mortality in elderly odontoid fractures. J Trauma 60:199203, 2006

37. Vaccaro AR, Madigan L, Ehrler DM: Contemporary management of adult cervical odontoid fractures. Orthopedics 23:1109-1113, 2000

38. Vasudevan K, Grossberg JA, Spader HS, Torabi R, Oyelese AA: Age increases the risk of immediate postoperative dysphagia and pneumonia after odontoid screw fixation. Clin Neurol Neurosurg 126:185-189, 2014

\section{Author Contributions}

Conception and design: both authors. Acquisition of data: both authors. Analysis and interpretation of data: both authors. Drafting the article: both authors. Critically revising the article: both authors. Reviewed submitted version of manuscript: both authors. Approved the final version of the manuscript on behalf of both authors: Joaquim. Study supervision: both authors.

\section{Correspondence}

Andrei F. Joaquim, Rua Antonio Lapa, 280, Sala 506, Campinas, SP CEP 13092-621, Brazil. email: andjoaquim@yahoo.com. 